\title{
Lino Kocijel
}

E-mail:1kocijel@gmail.com

Vedran Mrzljak

E-mail: vedran.mrzljak@riteh.hr

Faculty of Engineering, University of Rijeka, Vukovarska 58, 51000 Rijeka, Croatia

Maida Čohodar Husić

E-mail: cohodar@mef.unsa.ba

Ahmet Čekić

E-mail: cekic@mef.unsa.ba

Faculty of Mechanical Engineering, University of Sarajevo, Vilsonovo šetalište 9, 71000 Sarajevo, Bosnia and Herzegovina

\section{Numerical Analysis of Fuel Injector Nozzle Geometry \\ - Influence on Liquid Fuel Contraction Coefficient and Reynolds Number}

\begin{abstract}
This paper investigates the influence of the fuel injector nozzle geometry on the liquid fuel contraction coefficient and Reynolds number. The main three fuel injector nozzle geometry parameters: nozzle diameter $(d)$, nozzle length $(l)$ and nozzle inlet radius $(r)$ have a strong influence on the liquid fuel contraction coefficient and Reynolds number. The variation of the nozzle geometry variables at different liquid fuel pressures, temperatures and injection rates was analyzed. The liquid fuel contraction coefficient and Reynolds number increase with an increase in the nozzle diameter, regardless of the fuel injection rate. An increase in the $r / d$ ratio causes an increase in the fuel contraction coefficient, but the increase is not significant after $r / d=0.1$. A nozzle length increase causes a decrease in the fuel contraction coefficient. Increase in the nozzle length of $0.5 \mathrm{~mm}$ causes an approximately similar decrease in the contraction coefficient at any fuel pressure and any nozzle length. Fuel injectors should operate with minimal possible nozzle lengths in order to obtain higher fuel contraction coefficients.
\end{abstract}

Keywords: fuel injector, nozzle geometry, fuel contraction coefficient, Reynolds number 


\section{Introduction}

In internal combustion engines with a direct fuel injection the injector nozzle geometry strongly affects the fuel atomization process [1,2]. The liquid fuel atomization process has a strong influence on the engine combustion process $[3,4]$ and on exhaust emissions $[5,6]$. Correct understanding of the effects of the nozzle geometry on the fuel injection process is the basis for modeling fuel spray dynamics [7]. However, due to small length and time scales during the fuel injection process, it is still a challenge to capture and explain the physics behind those processes $[8,9]$.

The internal nozzle flow influence on spray atomization was investigated by several authors in the past $[10,11]$. A recent investigation of this topic is presented by Madero and Axelbaum [12] who investigated the fuel spray breakup and structure of spray flames for low-volatility wet fuels. Greenberg [13] investigated the impact of the initial droplet size distribution on the behavior of the edge flame.

Nozzle configuration effects on the internal flow and the primary spray breakup for flash boiling fuel sprays were analyzed by Wu et al. [14] while Abianeh et al. [15] investigated the nozzle flow influence and characteristics on the multi-component fuel spray evaporation process. Mrzljak and Žarković [16] presented a numerical model of the fuel spray penetration and fuel-air mixing process for a direct injection diesel engine, where the nozzle fuel flow influence produces one of the dominant effects on observed processes. An experimental study in fuel spray characteristics under atmospheric and pressurized cross-flow conditions was presented by Guo et al. [17].

The impact of the injector nozzle geometry on fuel injection, fuel atomization and evaporation processes must be involved in any detailed internal combustion engine simulation, as the one presented in [18] for a high speed direct injection turbocharged diesel engine. The same impact is inevitable in simulations of large marine two-stroke slow speed diesel engines $[19,20]$.

To reduce the internal combustion engine emissions and improve engine operating parameters, researchers have been intensely involved in implementing the combustion of different alternative fuels in existing engines [21, 22]. Insights into the dynamic structure of bio-diesel and conventional fuel sprays from high-pressure diesel injectors were investigated by Moon [23] while spray evaporation and penetration of alternative fuels were analyzed by Azami and Savill [24].

In this paper, the influence of the fuel injector nozzle geometry on the liquid fuel contraction coefficient and Reynolds number was investigated. The main three fuel injector nozzle geometry parameters: nozzle diameter $(d)$, nozzle length $(l)$ and nozzle inlet radius $(r)$ have a strong influence on the liquid fuel contraction coefficient and Reynolds number. The obtained results were presented for a variation of three nozzle geometry variables at different liquid fuel pressures, temperatures and injection rates. The results are compared and discussed in order to obtain a complete insight into the liquid fuel spray characteristics at the beginning of fuel injection. This analysis can be 
helpful in the optimization of injector nozzles according to fuel injection conditions for each particular internal combustion engine.

\section{Liquid fuel contraction coefficient}

The liquid fuel contraction is a liquid stream constriction that happens because the fluid streamlines cannot abruptly change direction [25]. Due to the fuel injector nozzle or a pipe diameter sudden change, fluid streamlines are unable to closely follow the sharp angle in the nozzle/pipe wall.

Maximum contraction is the place in a liquid fuel stream where the diameter of the stream has the lowest value and the liquid fuel velocity has the maximum value. The maximum contraction takes place in a section slightly downstream of the fuel injector nozzle, Fig. 1.

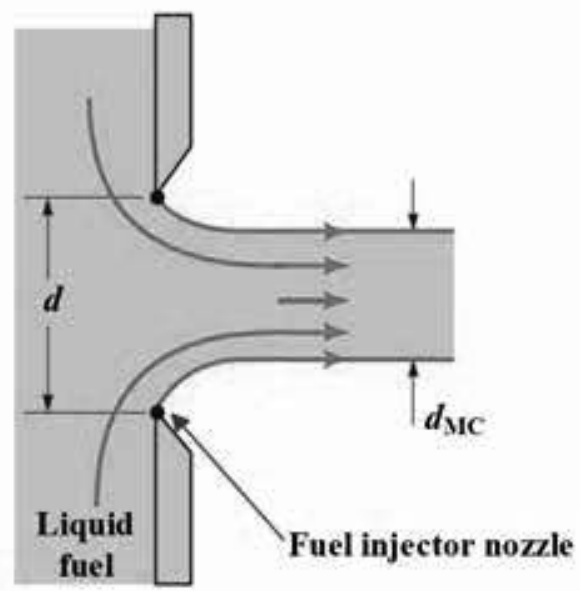

Figure 1 - Definition of the liquid fuel contraction coefficient for a fuel injector nozzle [26]

According to Fig. 1, the liquid fuel contraction coefficient for the fuel injector nozzle is defined as the ratio of the liquid fuel stream diameter at the maximum contraction point and the nozzle diameter:

$$
C_{\mathrm{d}}=\frac{d_{\mathrm{MC}}}{d},
$$

where:

$C_{\mathrm{d}}=$ liquid fuel contraction coefficient,

$d_{\mathrm{MC}}=$ liquid fuel stream diameter at the maximum contraction point,

$d=$ nozzle diameter. 
The liquid fuel contraction coefficient value is always lower than 1 and depends on the fuel stream parameters (pressure, temperature and injection rate) as well as on the nozzle geometry.

\section{Analyzed injector nozzle geometry parameters}

The intention of the presented mathematical model in this analysis is to be usable not only for one selected fuel injector and its nozzles, but rather for a large number of fuel injectors and for many liquid fuel types. The analysis baseline is the fuel injector DLLA 775 from [27] that has four identical nozzles and a cylindrical area under the injector needle.

The main three fuel injector nozzle geometry parameters that strongly influenced the liquid fuel contraction and Reynolds number are the nozzle diameter $(d)$, nozzle length $(l)$ and nozzle inlet radius $(r)$, presented in Fig. 2. With presented nozzle geometry parameters we can describe the liquid fluid flow characteristics through the nozzle and at the nozzle outlet. Each of these geometry parameters was varied to obtain a complete insight into its influence on the liquid fuel contraction and Reynolds number. The nozzle inlet radius usually has a small value and more often its value is not presented in millimeters, but is shown as the nozzle radius/diameter ratio $(r / d)$, which was also adopted in this analysis.

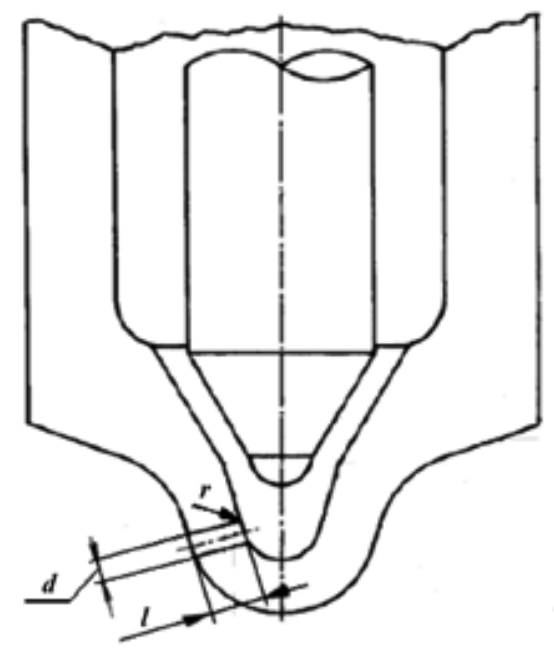

Figure 2 - Fuel injector section with analyzed nozzle geometry parameters 


\section{Liquid diesel fuel used in the analysis}

In the presented analysis a standard diesel fuel D2 is used, with its main characteristics and specifications as presented in Table 1. The liquid diesel fuel density increases with the pressure increase, but the dominant mechanism of the decrease in the liquid fuel density is caused by the increase in fuel temperature.

Although the analysis is made with a standard diesel fuel D2, mathematical description of the liquid fuel contraction coefficient and Reynolds number allows the usage of any standard or alternative liquid fuel, provided that changes are known concerning fuel density and dynamic viscosity depending on the current fuel pressure and temperature.

Table 1 - Main characteristics of diesel fuel D2 [28]

\begin{tabular}{|l|l|}
\hline Liquid diesel fuel D2 property & Value \\
\hline Boiling point & $266^{\circ} \mathrm{C}$ \\
\hline Molecular mass & $198 \mathrm{~kg} / \mathrm{kmol}$ \\
\hline Critical temperature & $453^{\circ} \mathrm{C}$ \\
\hline Critical pressure & $20.9 \mathrm{bar}$ \\
\hline Pour point & $-21.6^{\circ} \mathrm{C}$ \\
\hline Cloud point & $-15^{\circ} \mathrm{C}$ \\
\hline Sulphur content & 0.3 percentage of mass \\
\hline Density at $15.5^{\circ} \mathrm{C}$ & $0.842 \mathrm{~g} / \mathrm{cm}^{3}$ \\
\hline Kinematic viscosity at $38^{\circ} \mathrm{C}$ & $2.84 \cdot 10^{-6} \mathrm{~m}^{2} / \mathrm{s}$ \\
\hline Flash point & $75^{\circ} \mathrm{C}$ \\
\hline Aniline point & $71.7^{\circ} \mathrm{C}$ \\
\hline
\end{tabular}

\section{Liquid diesel fuel D2 thermodynamical properties necessary for the contraction coefficient and Reynolds number calculation}

\subsection{Liquid diesel fuel D2 density}

At high pressures of the fuel injected into the engine cylinder, liquid fuel density does not depend only on the liquid fuel temperature, but also on fuel pressure. The dependence of the liquid diesel fuel D2 density on the pressure and temperature is presented by the following expression [28]:

$$
\rho=\rho_{0} \cdot\left(1+\frac{p}{E}-\frac{\Delta t}{A}\right)
$$


where:

$\rho=$ liquid fuel current density $\left(\mathrm{g} / \mathrm{cm}^{3}\right)$,

$\rho_{0}=0.845 \mathrm{~g} / \mathrm{cm}^{3}$ (liquid fuel density on the environmental pressure and temperature),

$p=$ current pressure of liquid fuel $(\mathrm{Pa})$,

$E=19.6 \cdot 10^{8} \mathrm{~Pa}$ (liquid fuel elasticity module),

$\Delta t=$ liquid fuel temperature above the environment temperature which amounts $25^{\circ} \mathrm{C}$,

$A=1350{ }^{\circ} \mathrm{C}$ (reciprocal value of the liquid fuel thermal expansion coefficient).

\subsection{Liquid diesel fuel D2 dynamic viscosity}

The liquid fuel D2 dynamic viscosity dependence on fuel pressure and temperature is described by a diagram, which is digitized and units are converted into SI units. It has been observed by interpolation that the liquid fuel dynamic viscosity change can be described by a second degree polynomial whose coefficients are the function of the diesel fuel D2 temperature [28]:

$$
\begin{aligned}
& \mu=A(t)+B_{1}(t) \cdot p+B_{2}(t) \cdot p^{2}, \\
& A(t)=5.92723 \cdot 10^{-5}+0.0030803 \cdot \exp \left(-\frac{t-17.45789}{13.98351}\right)+0.0036761 \cdot \exp \left(-\frac{t-17.45789}{77.77}\right), \\
& B_{1}(t)=8.02964 \cdot 10^{-6}-1.17256 \cdot 10^{-7} \cdot t+3.82129 \cdot 10^{-10} \cdot t^{2}+1.30035 \cdot 10^{-12} \cdot t^{3}, \\
& B_{2}(t)=2.21756 \cdot 10^{-8} \cdot \exp \left(-\frac{t-20}{9.126829}\right)+5.85318 \cdot 10^{-9} \cdot \exp \left(-\frac{t-20}{51.453}\right),
\end{aligned}
$$

where:

$$
\begin{aligned}
& p=\text { current pressure of liquid fuel (bar), } \\
& t=\text { current temperature of liquid fuel }\left({ }^{\circ} \mathrm{C}\right), \\
& \mu=\text { liquid fuel current dynamic viscosity }(\mathrm{kg} / \mathrm{m} \cdot \mathrm{s}) .
\end{aligned}
$$

\section{Liquid fuel contraction coefficient and Reynolds number}

During the injection, the liquid fuel has a high pressure and injection rate and therefore the flow in the fuel injector nozzle is turbulent. Taking into account the turbulent flow in the fuel injector nozzle [29], the liquid fuel contraction coefficient can be defined as: 


$$
C_{\mathrm{d}}=\frac{1}{\sqrt{K_{\mathrm{in}}+f \cdot \frac{l}{d}+1}},
$$

where:

$C_{\mathrm{d}}=$ liquid fuel contraction coefficient (-),

$K_{\text {in }}=$ contraction loss coefficient, defined by Equation 8,

$f=$ Reynolds number coefficient, defined by Equation 9 ,

$l=$ nozzle length $(\mathrm{mm})$,

$d=$ nozzle diameter $(\mathrm{mm})$.

The contraction loss coefficient $K_{\text {in }}$ is a function of the nozzle inlet radius $r$ and the nozzle diameter $d$ ratio. According to [29] the contraction loss coefficient $K_{\text {in }}$ can be defined by the following polynomial:

$$
K_{\mathrm{in}}=162.52076 \cdot(r / d)^{4}-143.12017 \cdot(r / d)^{3}+47.86559 \cdot(r / d)^{2}-7.50909 \cdot(r / d)+0.51243,
$$

where:

$K_{\text {in }}=$ contraction loss coefficient (-),

$r=$ nozzle inlet radius $(\mathrm{mm})$,

$d=$ nozzle diameter $(\mathrm{mm})$.

The Reynolds number coefficient $f$ should be calculated by equation:

$$
f=\operatorname{Max}\left(0.316 \cdot \mathrm{Re}^{-0.25}, \frac{64}{\mathrm{Re}}\right),
$$

where Reynolds number is defined by the following expression:

$$
\operatorname{Re}=\frac{\rho \cdot v_{\mathrm{i}} \cdot d \cdot 10^{-3}}{\mu} .
$$

In Equation 10, the symbols are as follows:

$\rho=$ liquid fuel density $\left(\mathrm{kg} / \mathrm{m}^{3}\right)$,

$v_{\mathrm{i}}=$ liquid fuel injection rate $(\mathrm{m} / \mathrm{s})$,

$d=$ nozzle diameter $(\mathrm{mm})$,

$\mu=$ liquid fuel dynamic viscosity $(\mathrm{kg} / \mathrm{m} \cdot \mathrm{s})$. 


\section{Mathematical model results and discussion}

\subsection{Influence of changes in the nozzle diameter on the liquid fuel contraction coefficient and Reynolds number}

Fig. 3 presents changes in the liquid fuel contraction coefficient at different fuel pressures and nozzle diameters. The figure was obtained by using nozzle geometry and fuel characteristics presented in the boldface legend in the figure, for this one and any other figures. The fuel injection rate was $100 \mathrm{~m} / \mathrm{s}$.

The liquid fuel contraction coefficient increases with an increase in the nozzle diameter. It can be seen from Fig. 3 that the contraction coefficient continuously decreases with an increase in the liquid fuel pressure, for all the nozzle diameters observed. The decrease in the contraction coefficient during the fuel pressure increase has the sharpest value at the lowest observed nozzle diameter $(0.25 \mathrm{~mm})$, while at the highest observed nozzle diameter $(1 \mathrm{~mm})$ the increase in the fuel pressure has a low impact on the contraction coefficient decrease.

For presented fuel and nozzle operating parameters, the highest contraction coefficient was obtained at the highest nozzle diameter and the lowest fuel pressure (1 $\mathrm{mm}$ and 500 bars) while the lowest contraction coefficient was obtained at the lowest nozzle diameter and highest fuel pressure $(0.25 \mathrm{~mm}$ and $2000 \mathrm{bar})$. The fuel injection pressure in internal combustion engines today exceeds $1500 \mathrm{bar}$, so that the fuel pressure of 500 bars cannot be used as a relevant one, but only can be presented as the result of a numerical analysis.

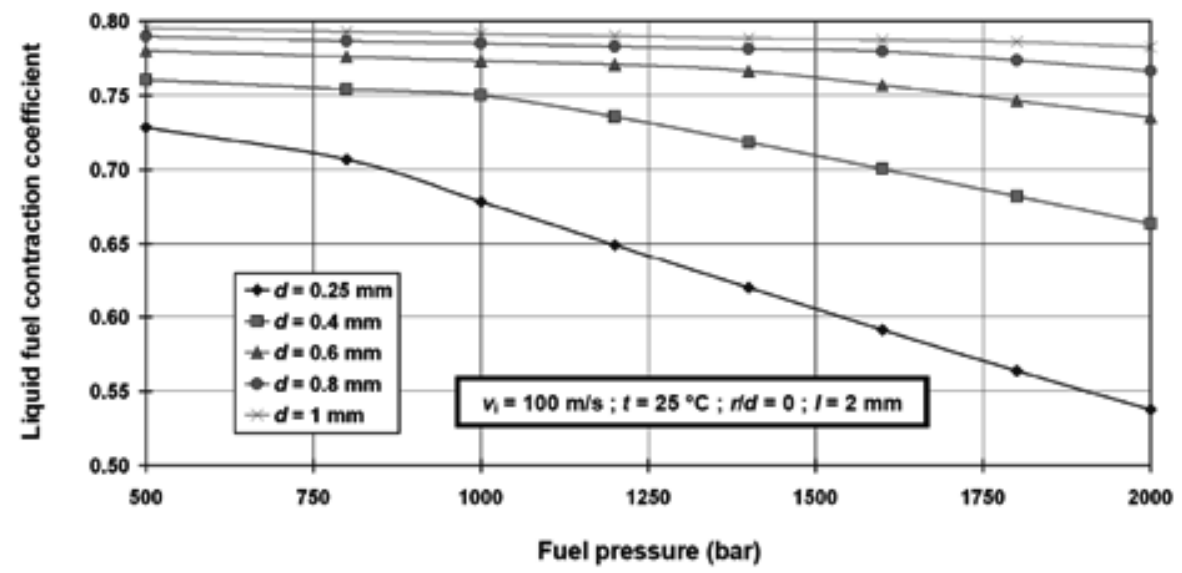

Figure 3 - Changes in the liquid fuel contraction coefficient at different fuel pressures and nozzle diameters $\left(v_{\mathrm{i}}=100 \mathrm{~m} / \mathrm{s}\right)$ 
Fig. 4 shows the liquid fuel contraction coefficient calculation for the same input parameters as in Fig. 3, yet for a three times higher fuel injection rate $(300 \mathrm{~m} / \mathrm{s})$. The same general conclusions from Fig. 3 are also valid for Fig. 4, with a remark that the three times higher injection rate does not cause any proportional change in the contraction coefficient.

The increase in the fuel injection rate from $100 \mathrm{~m} / \mathrm{s}$ (Fig. 3) to $300 \mathrm{~m} / \mathrm{s}$ (Fig. 4) only causes a slight increase in the liquid fuel contraction coefficient for most nozzle diameters observed, at lower pressures observed. The most notable increase in the contraction coefficient in comparison with the lower injection rate can be seen for the lowest nozzle diameters $(0.25 \mathrm{~mm}$ and $0.4 \mathrm{~mm})$ at fuel pressures higher than 1000 bar.

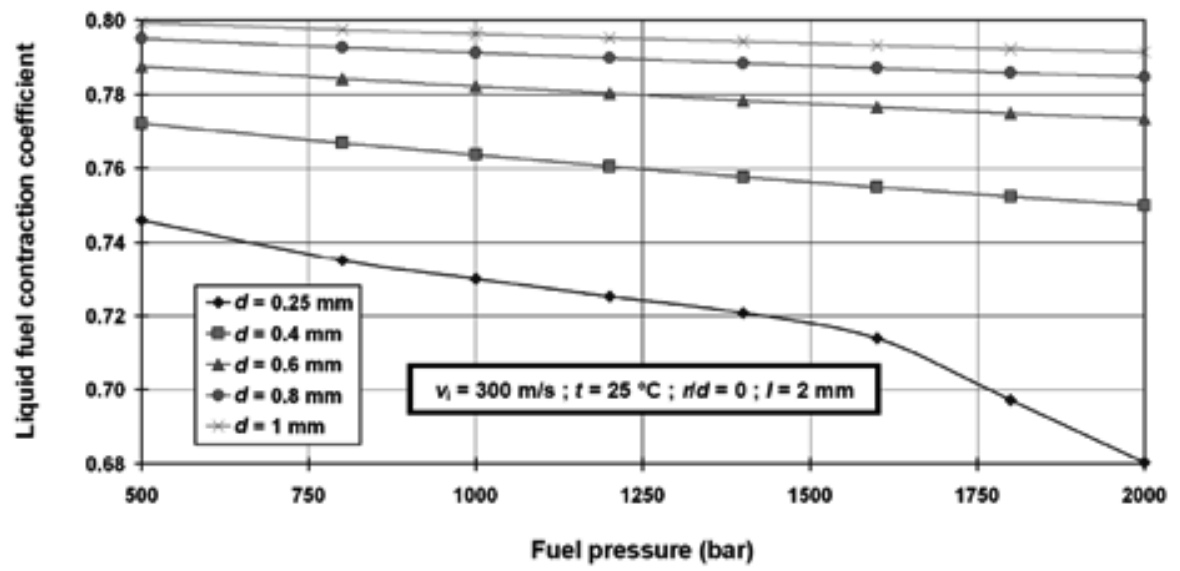

Figure 4 - Changes in the liquid fuel contraction coefficient at different fuel pressures and nozzle diameters $\left(v_{\mathrm{i}}=300 \mathrm{~m} / \mathrm{s}\right)$

For the same input parameters presented in Fig. $3\left(v_{\mathrm{i}}=100 \mathrm{~m} / \mathrm{s}\right)$, changes in the Reynolds number follow the same trend in the contraction coefficient, as presented in Fig. 5. For any of the observed nozzle diameters, the Reynolds number decreases during the increase in fuel pressure. The highest decrease in Reynolds number during the fuel pressure increase can be observed at the highest nozzle diameter $(1 \mathrm{~mm})$ from approximately $\mathrm{Re}=7000$ at fuel pressure of 500 bars to $\mathrm{Re}=1000$ at fuel pressure of 2000 bar.

The decrease in Reynolds number during the fuel pressure increase follows the decrease in the nozzle diameter, so that the lowest decrease in Reynolds number from 500 to 2000 bar can be seen at the lowest observed nozzle diameter $(0.25 \mathrm{~mm})$. At the highest observed fuel pressure of 2000 bar, Reynolds number has a low dispersion and amounts between $\mathrm{Re}=300$ and $\mathrm{Re}=1000$ for any nozzle diameter. 


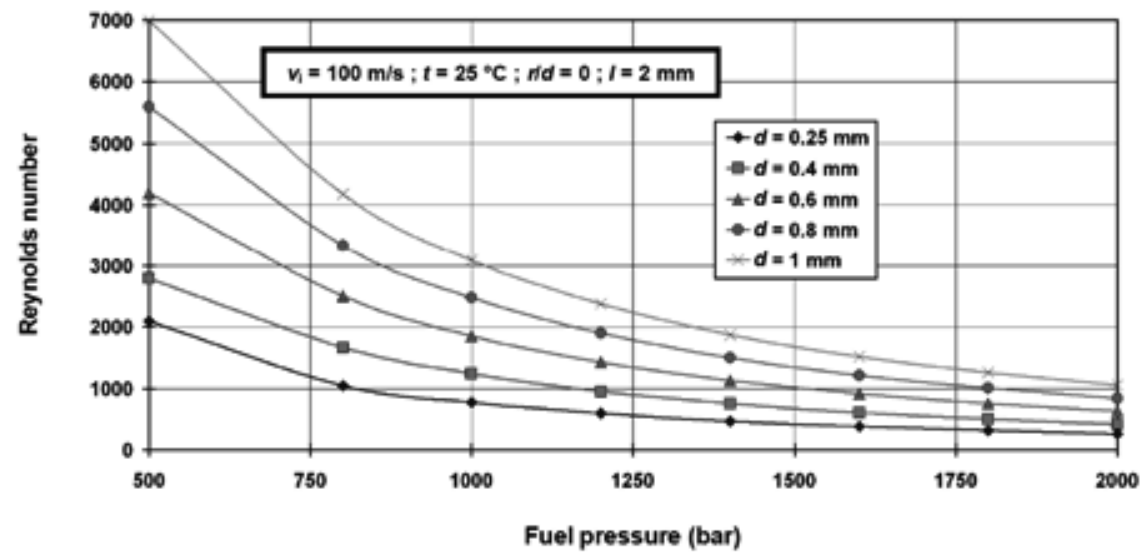

Figure 5 - Changes in Reynolds number at different fuel pressures and nozzle diameters $\left(v_{\mathrm{i}}=100 \mathrm{~m} / \mathrm{s}\right)$

A three times increase in the fuel injection rate with other fuel and injector variables unchanged, in comparison with Fig. 5, resulted in a three times higher Reynolds number, as presented in Fig. 6, for all nozzle diameters. According to Equation 10 , this is an expected trend. Again, any general conclusions valid for the fuel injection rate of $100 \mathrm{~m} / \mathrm{s}$ (Fig. 5) are also valid for the fuel injection rate of $300 \mathrm{~m} / \mathrm{s}$ (Fig. 6). During the fuel pressure increase, the decrease in Reynolds number follows the nozzle diameter increase.

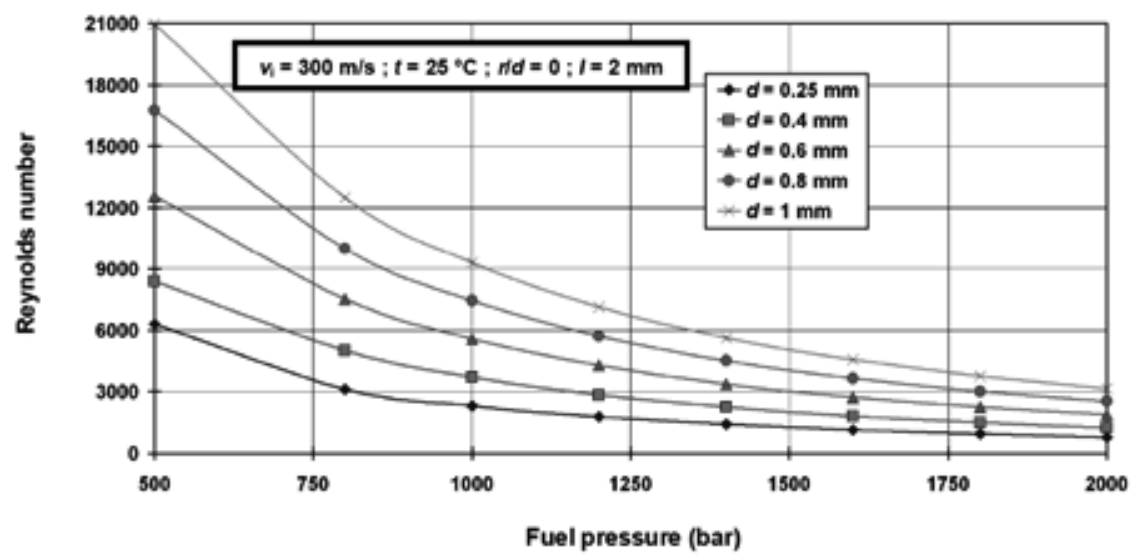

Figure 6 - Changes in Reynolds number at different fuel pressures and nozzle diameters $\left(v_{\mathrm{i}}=300 \mathrm{~m} / \mathrm{s}\right)$ 
The conclusion that can be derived from the variation in the injector nozzle diameter is that the contraction coefficient and Reynolds number increase with an increase in the nozzle diameter, regardless of the fuel injection rate. An increase in fuel pressure causes a decrease both in the contraction coefficient and in Reynolds number at every observed nozzle diameter. Increase in the fuel injection rate is directly proportional to the increase in Reynolds number. Increase in the fuel injection rate causes a slight increase in the fuel contraction coefficient at lower fuel pressures and a significant increase in the fuel contraction coefficient at higher fuel pressures, but the increase is not proportional to the injection rate increase for the entire fuel pressure range observed.

\subsection{Influence of changes in the radius/diameter ratio on the liquid fuel contraction coefficient}

A change in the nozzle radius/diameter $(r / d)$ ratio does not affect Reynolds number and therefore this section presents the influence of the radius/diameter ratio on the liquid fuel contraction coefficient for several fuel and fuel injector nozzle operating parameters.

Fig. 7 presents changes in the liquid fuel contraction coefficient at different fuel pressures and radius/diameter ratios at the fuel injection rate of $100 \mathrm{~m} / \mathrm{s}$ and nozzle diameter of $0.25 \mathrm{~mm}$. The contraction coefficient increases during an increase in the $r / d$ ratio, so the highest contraction coefficient can be seen in the highest observed $r / d$ ratio at any fuel pressure. This result can be explained by the fact that liquid fuel streamlines can follow more precisely the nozzle edges that are of a more rounded shape.

An increase in fuel pressure causes a sharp decrease in the contraction coefficient at any $r / d$ ratio. It can be concluded from Fig. 7 that the optimal $r / d$ ratio for observed operating parameters is $r / d=0.1$ because an additional increase in the $r / d$ ratio increases the contraction coefficient by a very small, insignificant value. 


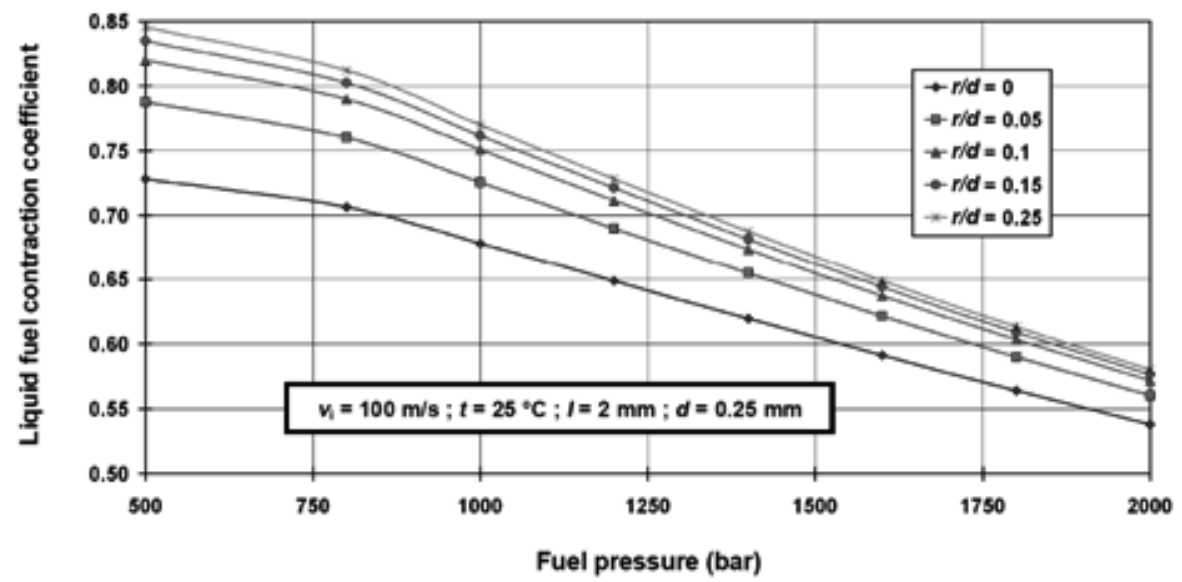

Figure 7 - Changes in the liquid fuel contraction coefficient at different fuel pressures and radius/diameter ratios $\left(v_{\mathrm{i}}=100 \mathrm{~m} / \mathrm{s}, d=0.25 \mathrm{~mm}\right)$

When all the nozzle and fuel operating parameters remained the same as in Fig. 7 and the injection rate increased from $100 \mathrm{~m} / \mathrm{s}$ to $300 \mathrm{~m} / \mathrm{s}$, results were obtained as presented in Fig. 8. Here again, general conclusions remain the same as for the lower injection rate - an increase in the $r / d$ ratio increases the contraction coefficient. The most significant increase in the contraction coefficient is from $r / d=0$ to $r / d=0.1$. A further increase in the $r / d$ ratio does not have any significant influence on the contraction coefficient increase.

An increase in fuel pressure causes a decrease in the contraction coefficient at any $r / d$ ratio, but the decrease is not as sharp as at the injection rate of $100 \mathrm{~m} / \mathrm{s}$. At a higher fuel injection rate, the contraction coefficient increases at any $r / d$ ratio (Fig. 8) and at any fuel pressure when compared with the lower injection rate (Fig. 7). 


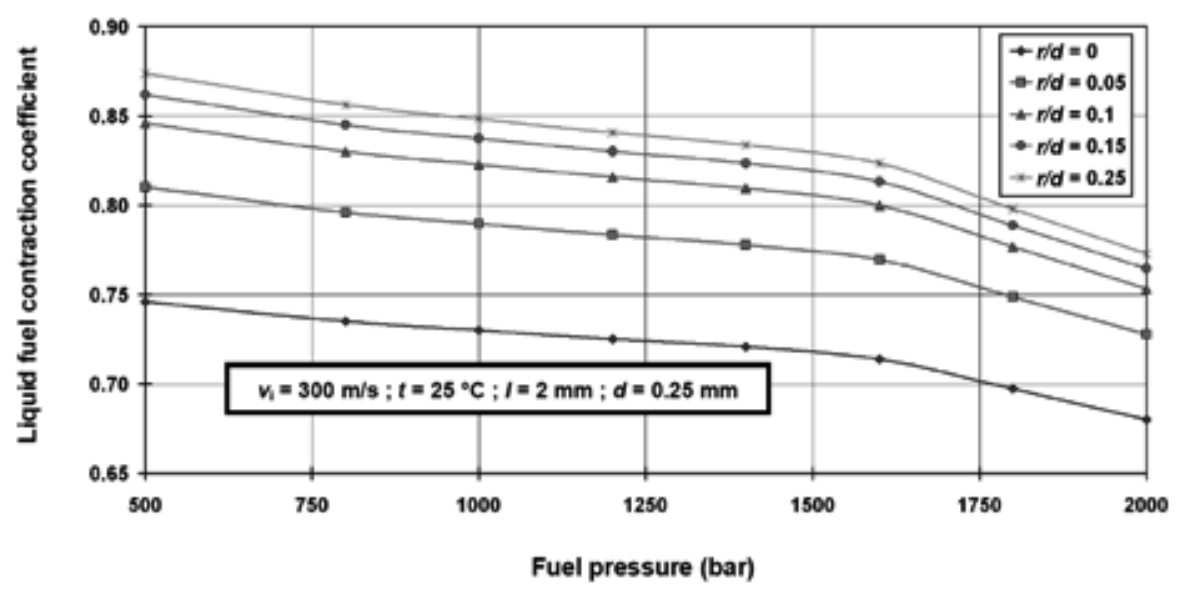

Figure 8 - Changes in the liquid fuel contraction coefficient at different fuel pressures and radius/diameter ratios $\left(v_{\mathrm{i}}=300 \mathrm{~m} / \mathrm{s}, d=0.25 \mathrm{~mm}\right)$

A change in the liquid fuel contraction coefficient at different fuel pressures and radius/diameter ratios at an increased nozzle diameter $(0.6 \mathrm{~mm})$ is presented in Fig. 9 and in Fig. 10 for the injection rate of $100 \mathrm{~m} / \mathrm{s}$ and $300 \mathrm{~m} / \mathrm{s}$ respectively.

As can be seen from these two figures that the increase in the nozzle diameter (from $0.25 \mathrm{~mm}$ to $0.6 \mathrm{~mm}$ ) increases the liquid fuel contraction coefficient at any fuel pressure and any $r / d$ ratio. As noted earlier, the highest contraction coefficient is obtained at the highest $r / d$ ratio. The increase in fuel pressure causes a decrease in the contraction coefficient, which is sharper at a lower injection rate (Fig. 9), while a decrease in the contraction coefficient is linear at a higher fuel injection rate (Fig. 10) at any $r / d$ ratio. An increase in an $r / d$ ratio above $r / d=0.1$ causes a low increase in the contraction coefficient at any fuel pressure, regardless of the injection rate.

It results from Fig. 9 and Fig. 10 that at the same nozzle diameter and at the same $r / d$ ratio the contraction coefficient is a little higher at a higher fuel injection rate, so that a significant increase in the injection rate does not have any significant influence on the contraction coefficient increase. An increase in the fuel pressure at the selected fuel and injector nozzle operating parameters does not cause any significant change in the fuel contraction coefficient at a higher injection rate, at any $r / d$ ratio, Fig. 10. 


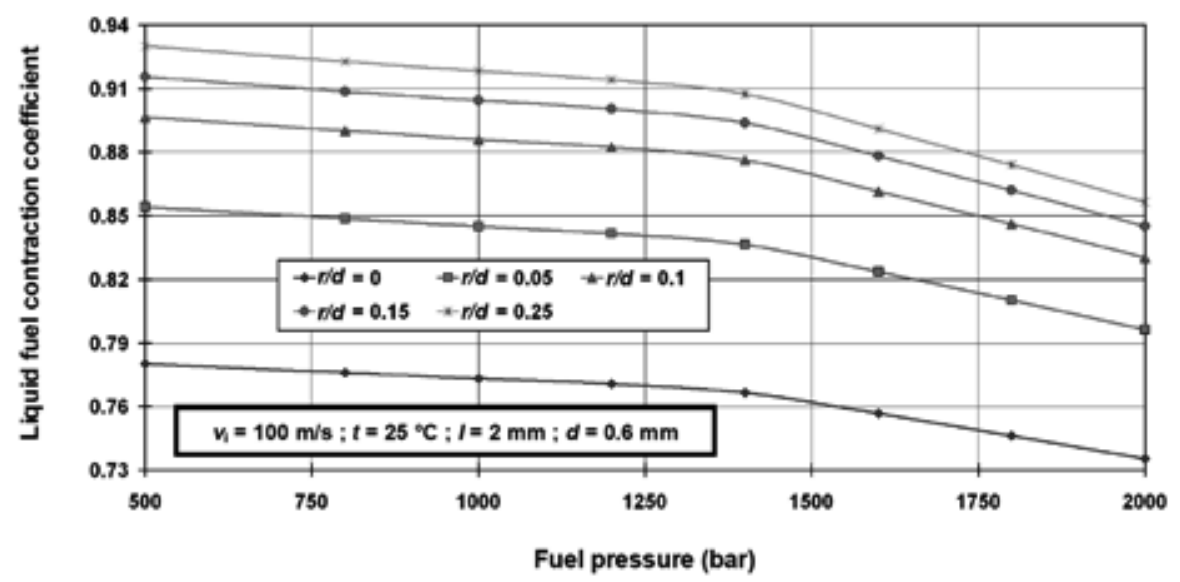

Figure 9 - Changes in the liquid fuel contraction coefficient at different fuel pressures and radius/diameter ratios $\left(v_{\mathrm{i}}=100 \mathrm{~m} / \mathrm{s}, d=0.6 \mathrm{~mm}\right)$

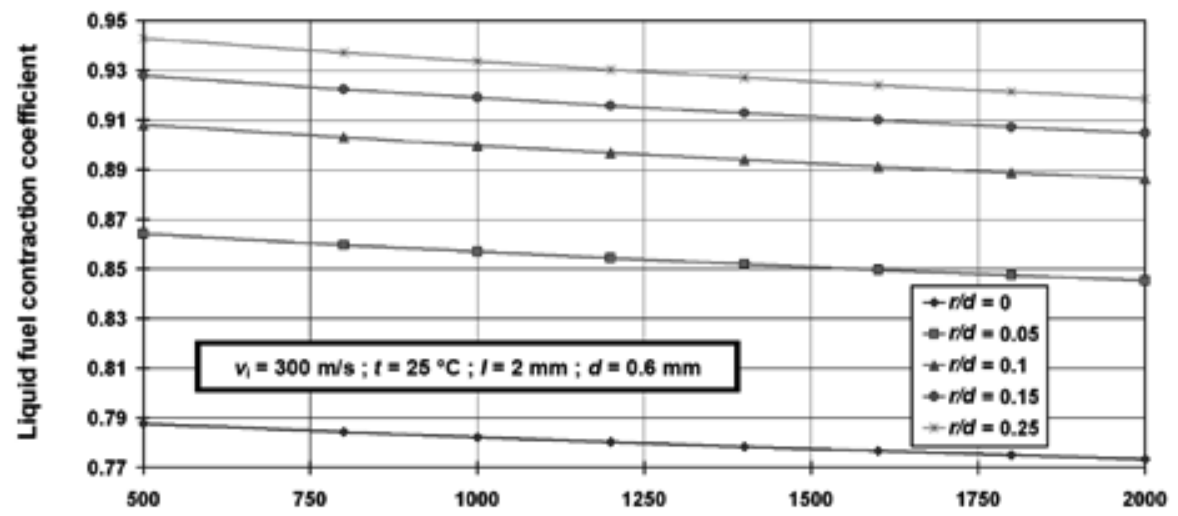

Fuel pressure (bar)

Figure 10 - Changes in the liquid fuel contraction coefficient at different fuel pressures and radius/diameter ratios $\left(v_{\mathrm{i}}=300 \mathrm{~m} / \mathrm{s}, d=0.6 \mathrm{~mm}\right)$

A change in the liquid fuel contraction coefficient at different fuel pressures and radius/diameter ratios at the highest observed nozzle diameter of $1 \mathrm{~mm}$ is presented in Fig. 11 for the injection rate of $100 \mathrm{~m} / \mathrm{s}$ and in Fig. 12 for the injection rate of $300 \mathrm{~m} / \mathrm{s}$.

At any fuel pressure and injection rate, an increase in the nozzle diameter (from $0.6 \mathrm{~mm}$ to $1 \mathrm{~mm}$ ) at any $r / d$ ratio increases the liquid fuel contraction coefficient. The nozzle diameter of $1 \mathrm{~mm}$ causes the contraction coefficient to approach its maximal value for the highest $r / d$ ratio. Here again, at the highest observed nozzle diameter, 
any increase in the $r / d$ ratio above $r / d=0.1$ causes a low increase in the contraction coefficient at any fuel pressure, regardless of the injection rate. An increase in the fuel pressure for the selected fuel, injector nozzle operating parameters and nozzle diameter of $1 \mathrm{~mm}$ does not cause any significant change in the fuel contraction coefficient at either injection rate observed and at any $r / d$ ratio. At a higher fuel injection rate and any $r / d$ ratio, the contraction coefficient is higher in comparison with a lower injection rate, yet the difference is almost negligible.

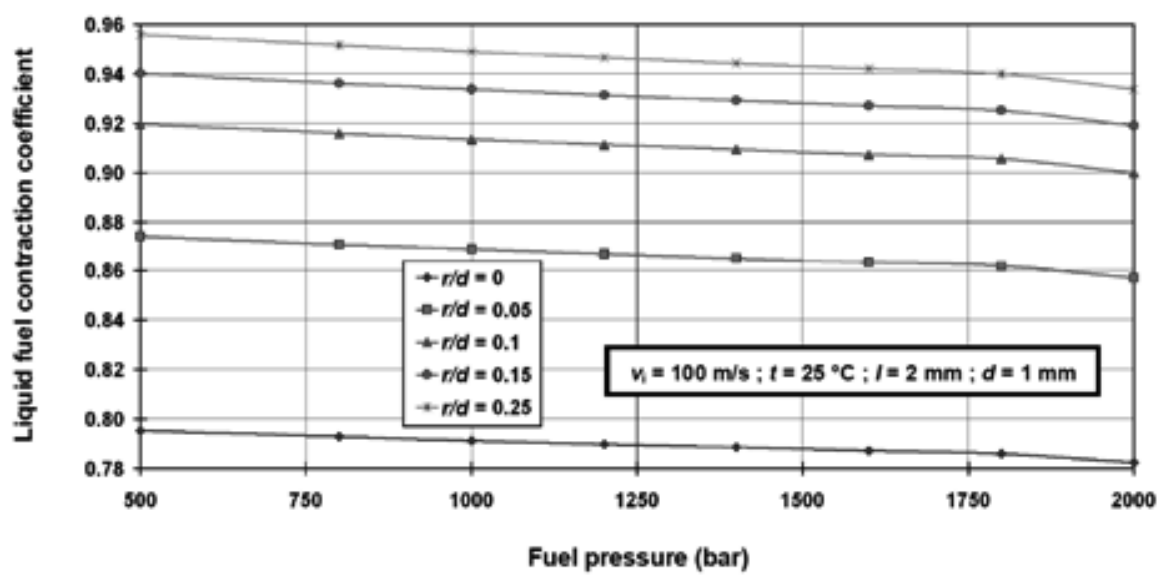

Figure 11 - Changes in the liquid fuel contraction coefficient at different fuel pressures and radius/diameter ratios $\left(v_{\mathrm{i}}=100 \mathrm{~m} / \mathrm{s}, d=1 \mathrm{~mm}\right)$

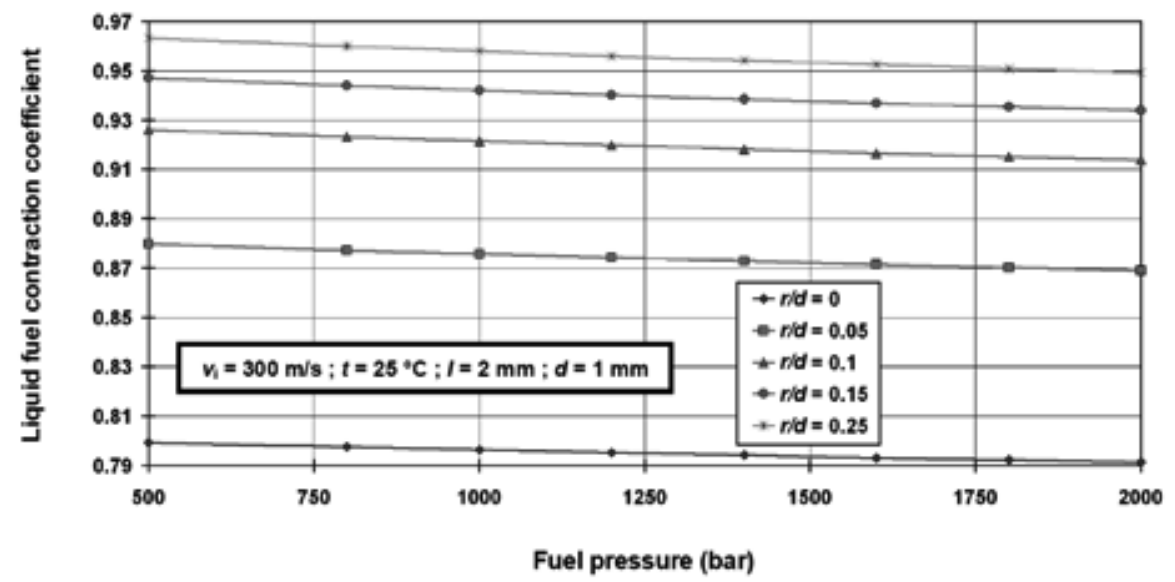

Figure 12 - Changes in the liquid fuel contraction coefficient at different fuel pressures and radius/diameter ratios $\left(v_{\mathrm{i}}=300 \mathrm{~m} / \mathrm{s}, d=1 \mathrm{~mm}\right)$ 
The influence of the nozzle radius/diameter ratio on the fuel contraction coefficient is presented for several nozzle diameters and injection rates. An increase in the $r / d$ ratio causes an increase in the contraction coefficient, but that increase is not significant after $r / d=0.1$. For higher nozzle diameters and for all $r / d$ ratios, a significant increase in the fuel injection rate does not have a major influence on the contraction coefficient. An increase in the fuel pressure reduces the fuel contraction coefficient at any $r / d$ ratio, what is even more significant at lower nozzle diameters. For higher nozzle diameters, an increase in the fuel pressure reduces the fuel contraction coefficient, but the reduction is almost negligible, which is valid for all $r / d$ ratios.

\subsection{Influence of changes in the nozzle length on the liquid fuel contraction coefficient}

As well as the change in the nozzle radius/diameter ratio, the change in the nozzle length does not affect the Reynolds number. Therefore, in this section the influence of the nozzle length on the fuel contraction coefficient is presented for several fuel and fuel injector nozzle operating parameters.

A change in the liquid fuel contraction coefficient at different fuel pressures and nozzle lengths at the fuel injection rate of $100 \mathrm{~m} / \mathrm{s}$ is presented in Fig. 13. In general, an increase in the nozzle length causes a decrease in the fuel contraction coefficient. It can be seen in Fig. 13 that an increase in the nozzle length by $0.5 \mathrm{~mm}$ causes an approximately similar decrease in the contraction coefficient at any fuel pressure value.

An increase in fuel pressure causes a sharp decrease in the contraction coefficient at any nozzle length and nozzle diameter of $0.25 \mathrm{~mm}$, Fig. 13. It can be concluded that it will be most appropriate for fuel injectors to operate with a minimal possible nozzle lengths, to obtain higher fuel contraction coefficients, regardless of the fuel injection pressure. 


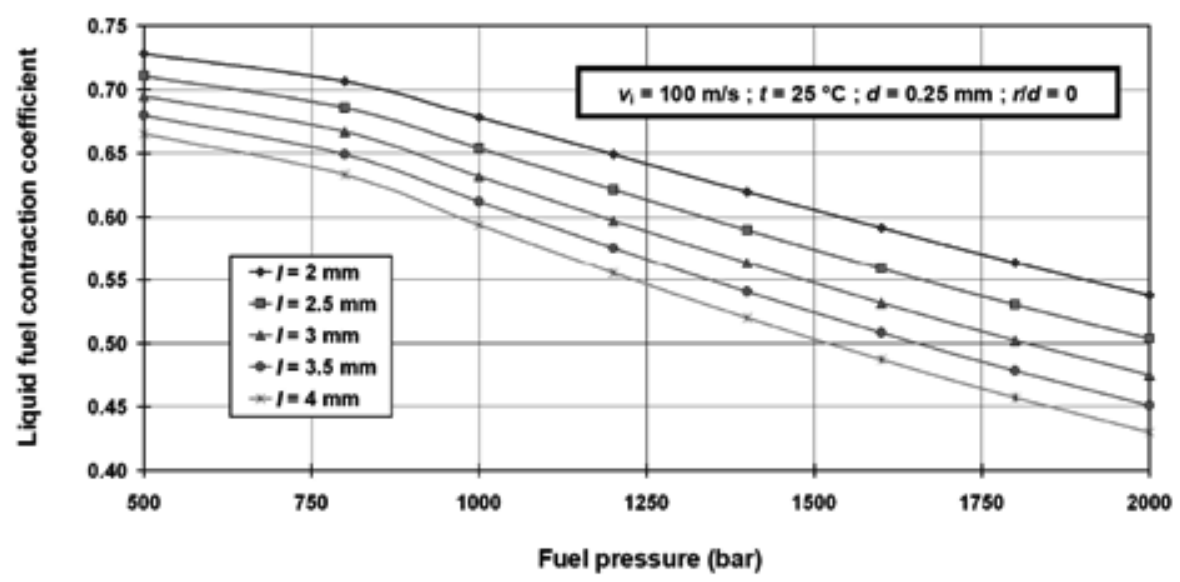

Figure 13 - Changes in the liquid fuel contraction coefficient at different fuel pressures and nozzle lengths $\left(v_{\mathrm{i}}=100 \mathrm{~m} / \mathrm{s}, d=0.25 \mathrm{~mm}\right)$

If the fuel and fuel injection nozzle operating parameters remain the same as in Fig. 13, and the fuel injection rate increases three times to $300 \mathrm{~m} / \mathrm{s}$, the contraction coefficient slightly increases at lower fuel pressures and strongly increases at higher fuel pressures in comparison with an injection rate of $100 \mathrm{~m} / \mathrm{s}$, Fig. 14, at each nozzle length. An increase in the nozzle length of $0.5 \mathrm{~mm}$ causes an approximately similar decrease in the contraction coefficient at every fuel pressure. With an increase in the fuel pressure, the contraction coefficient decreases at any nozzle length, but the decrease is not as sharp at the injection rate of $300 \mathrm{~m} / \mathrm{s}$ as at $100 \mathrm{~m} / \mathrm{s}$.

It can be concluded from Fig. 13 and Fig. 14 that the fuel injection rate is a very influential parameter for fuel injectors with small nozzle diameters and high fuel pressures. As already said, the recommendation is to use fuel injectors with the lowest possible nozzle lengths to obtain higher fuel contraction coefficients. 


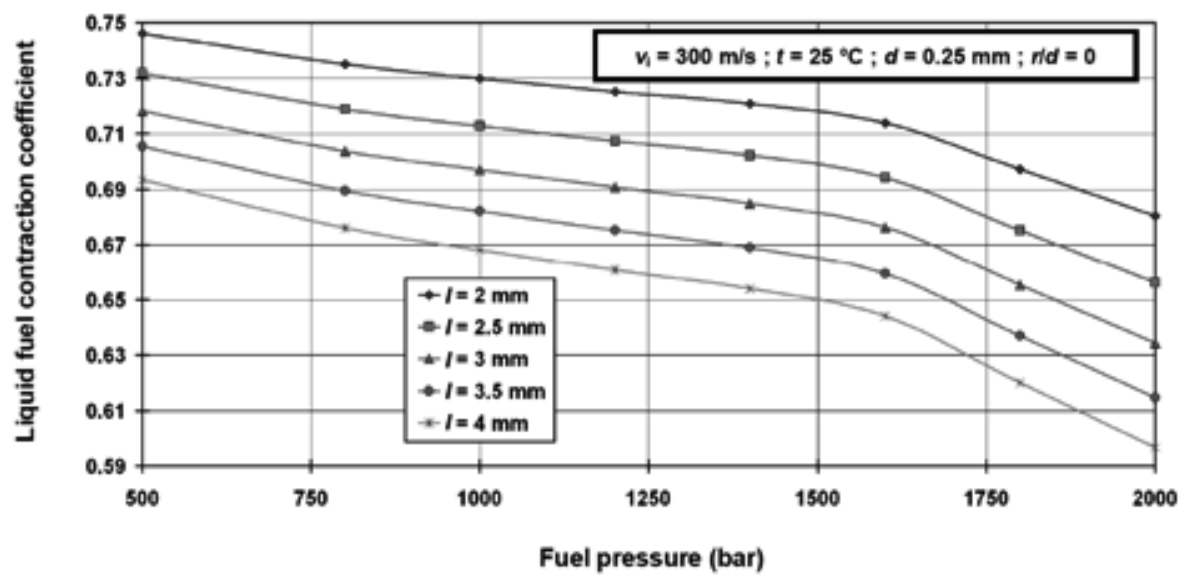

Figure 14 - Changes in the liquid fuel contraction coefficient at different fuel pressures and nozzle lengths $\left(v_{\mathrm{i}}=300 \mathrm{~m} / \mathrm{s}, d=0.25 \mathrm{~mm}\right)$

Changes in the liquid fuel contraction coefficient at different fuel pressures and nozzle lengths at the increased nozzle diameter $(d=0.6 \mathrm{~mm})$ in comparison with the previously analyzed ones are presented in Fig. 15 and Fig. 16 for injection rates of 100 $\mathrm{m} / \mathrm{s}$ and $300 \mathrm{~m} / \mathrm{s}$ respectively.

The general conclusion remains the same - an increase in the nozzle length causes a decrease in the fuel contraction coefficient. At each selected pressure, an increase in the nozzle length of $0.5 \mathrm{~mm}$ causes an approximately equal decrease in the contraction coefficient, regardless of the injection rate.

A comparison of Fig. 15 and Fig 16 can make us conclude that an increase in fuel pressure at any nozzle length causes a continuous decrease in the contraction coefficient which results sharper at a lower injection rate. For higher pressures observed, the injection rate increase has still an important influence on the increase in the contraction coefficient, but that influence is not as significant as for lower nozzle diameters, as can be seen at each nozzle length.

In addition, at higher fuel injection rates, Fig. 16, a fuel pressure increase causes a continuous yet almost negligible decrease in the contraction coefficient, at any nozzle length observed. 


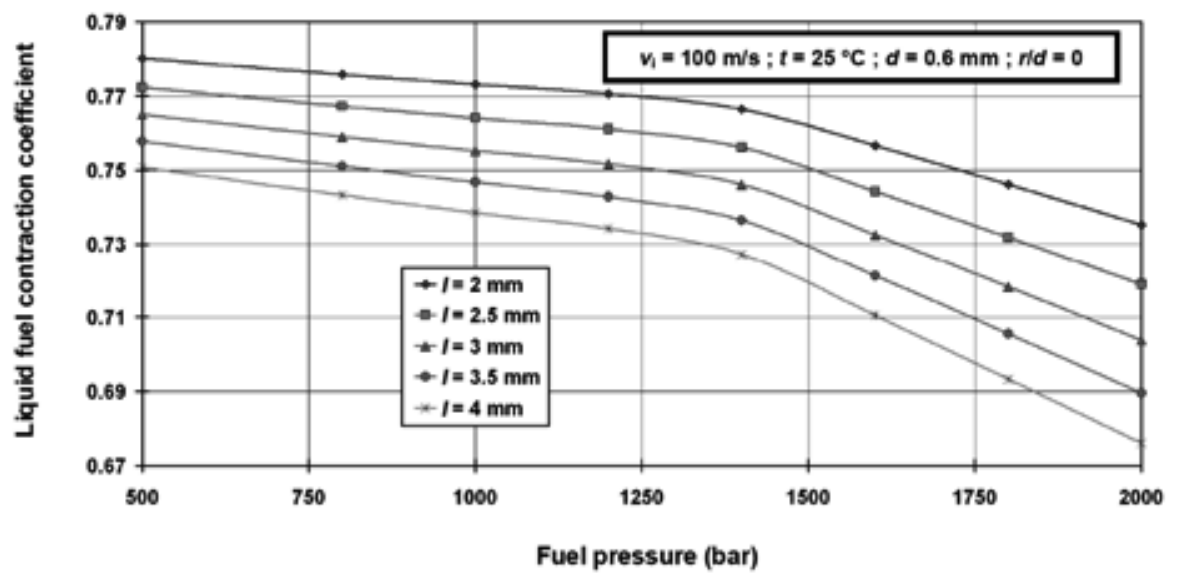

Figure 15 - Changes in the liquid fuel contraction coefficient at different fuel pressures and nozzle lengths $\left(v_{\mathrm{i}}=100 \mathrm{~m} / \mathrm{s}, d=0.6 \mathrm{~mm}\right)$

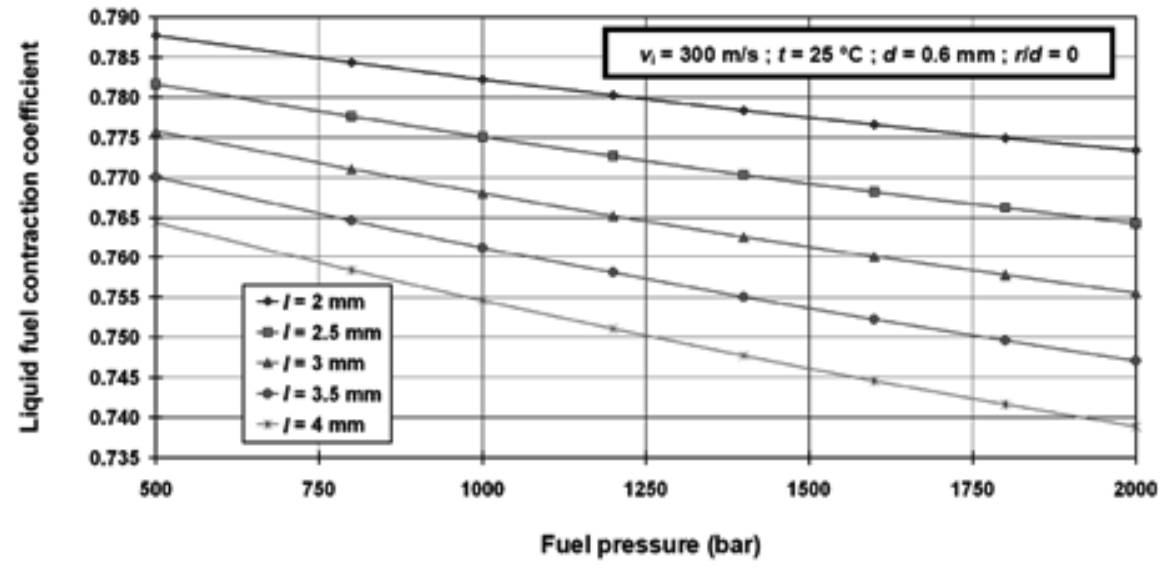

Figure 16 - Changes in the liquid fuel contraction coefficient at different fuel pressures and nozzle lengths $\left(v_{\mathrm{i}}=300 \mathrm{~m} / \mathrm{s}, d=0.6 \mathrm{~mm}\right)$

At the end, the change in the liquid fuel contraction coefficient is presented at different fuel pressures and nozzle lengths for the highest nozzle diameter observed ( $d$ $=1 \mathrm{~mm}$ ). Fig. 17 and Fig. 18 present the influence of the nozzle length change at the injection rate of $100 \mathrm{~m} / \mathrm{s}$ and $300 \mathrm{~m} / \mathrm{s}$ respectively.

Conclusions are identical as for lower nozzle diameters with the remark that an increase in the fuel pressure causes a lower decrease in the contraction coefficient 
following the nozzle diameter increase, at any nozzle length. The increase in the contraction coefficient at higher injection rates and the same nozzle lengths drops as the nozzle diameter increases.

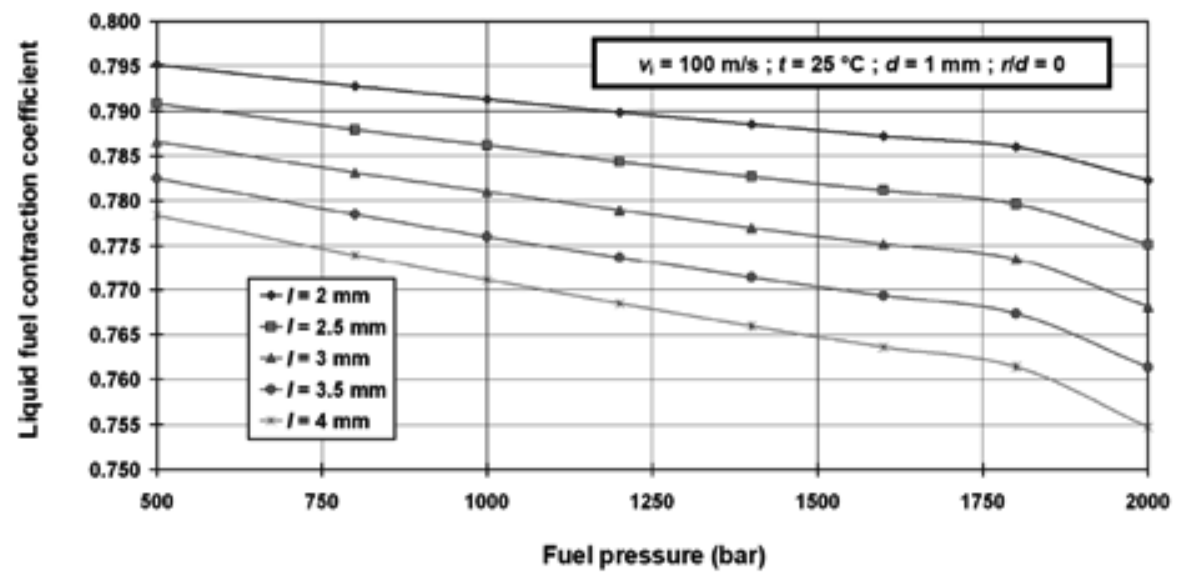

Figure 17 - Changes in the liquid fuel contraction coefficient at different fuel pressures and nozzle lengths $\left(v_{\mathrm{i}}=100 \mathrm{~m} / \mathrm{s}, d=1 \mathrm{~mm}\right)$

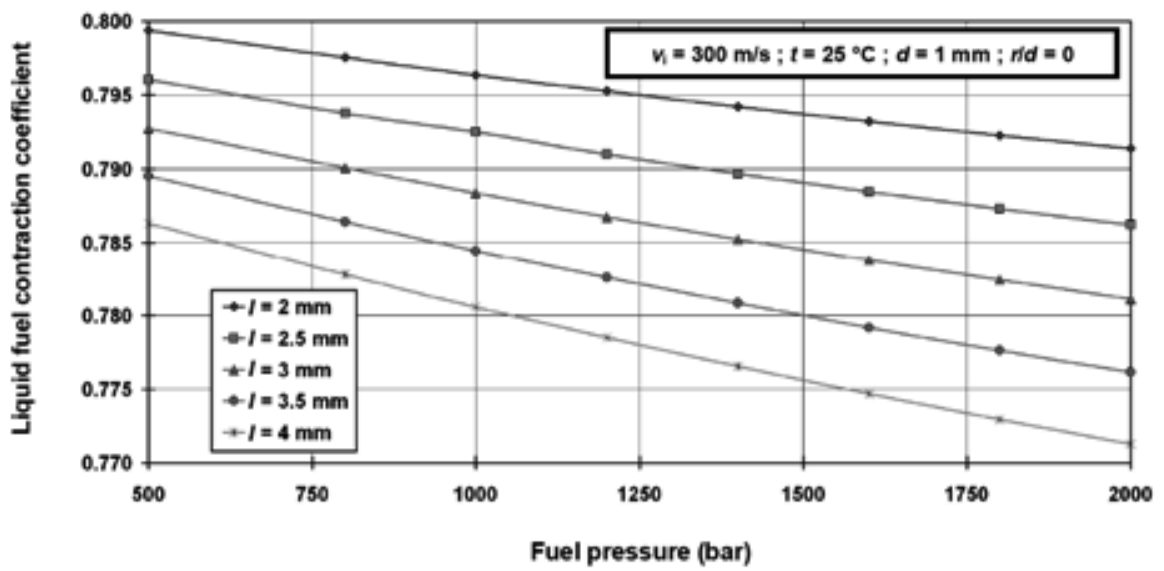

Figure 18 - Changes in the liquid fuel contraction coefficient at different fuel pressures and nozzle lengths $\left(v_{\mathrm{i}}=300 \mathrm{~m} / \mathrm{s}, d=1 \mathrm{~mm}\right)$

In general, for any fuel and fuel injector operating parameters an increase in the nozzle length causes a decrease in the fuel contraction coefficient. An increase in the nozzle length of $0.5 \mathrm{~mm}$ causes an approximately similar decrease in the contraction 
coefficient at any fuel pressure and any nozzle length. With an increase in the fuel pressure, the contraction coefficient decreases at any nozzle length, and as the nozzle diameter increases, the increase in the fuel pressure causes a lower decrease in the contraction coefficient. The increase in the contraction coefficient at higher injection rates and the same nozzle lengths gets lower as the nozzle diameter increases. It can be concluded that it will be most appropriate for fuel injectors to operate with minimal possible nozzle lengths, to obtain higher fuel contraction coefficients, regardless of the fuel injection pressure.

\section{Conclusion}

The fuel injector nozzle geometry influence on the liquid fuel contraction coefficient and Reynolds number was investigated and presented in this paper. The main three fuel injector nozzle geometry parameters: nozzle diameter $(d)$, nozzle length $(l)$ and nozzle inlet radius $(r)$ have a strong influence on the liquid fuel contraction coefficient and Reynolds number. Variation results of the three nozzle geometry variables at different liquid fuel pressures, temperatures and injection rates were presented and discussed.

The liquid fuel contraction coefficient and Reynolds number increase with the increase in the nozzle diameter, regardless of the fuel injection rate. The fuel pressure increase resulted in the decrease in both the contraction coefficient and Reynolds number at any nozzle diameter observed. An increase in the fuel injection rate causes a slight increase in the fuel contraction coefficient at lower fuel pressures and a significant increase in the fuel contraction coefficient at higher fuel pressures at each nozzle diameter observed. Likewise, the increase in the fuel injection rate is directly proportional to the increase in the Reynolds number at each nozzle diameter.

An increase in the $r / d$ ratio causes an increase in the contraction coefficient, but that increase is not significant after $r / d=0.1$. For higher nozzle diameters, a significant increase in the fuel injection rate does not have a major influence on the contraction coefficient increase, at any $r / d$ ratio. An increase in fuel pressure significantly reduces the fuel contraction coefficient at lower nozzle diameters, while at higher nozzle diameters the increase in fuel pressure reduces the fuel contraction coefficient, but the reduction is almost negligible, at any $r / d$ ratio.

For the selected fuel and fuel injector operating parameters, an increase in the nozzle length causes a decrease in the fuel contraction coefficient. An increase in the nozzle length of $0.5 \mathrm{~mm}$ causes an approximately similar decrease in the contraction coefficient at any fuel pressure and any nozzle length. An increase in fuel pressure causes a decrease at any nozzle length. At each nozzle length observed, any increase in the nozzle diameter and fuel pressure resulted in a lower decrease in the contraction coefficient. As the nozzle diameter increases, the increase in the contraction coefficient at higher injection rates and the same nozzle lengths is lower. It can be recommended that fuel injectors should operate with minimal possible nozzle lengths in order to obtain higher fuel contraction coefficients. 


\section{Acknowledgments}

This research has been supported by the Croatian Science Foundation under the project IP-2018-01-3739, CEEPUS network CIII-HR-0108, the European Regional Development Fund under the grant KK.01.1.1.01.0009 (DATACROSS) and the University of Rijeka scientific grant uniri-tehnic-18-275-1447.

\section{References}

1. Senčić, T., Mrzljak, V., Blecich, P., Bonefačić, I.: 2D CFD Simulation of Water Injection Strategies in a Large Marine Engine, Journal of Marine Science and Engineering, 7, 296, 2019. (doi:10.3390/ jmse7090296)

2. Mrzljak, V., Žarković, B.: Naturally aspirated gasoline engine upgrade with turbocharger - numerical investigation of change in operating parameters, XXVI International Scientific Conference - Trans \& MOTAUTO '18 - Proceedings, Sofia, Bulgaria, p. 60-63, 2018.

3. Rajak, U., Nashine, P., Singh, T. S., Verma, T. N.: Numerical investigation of performance, combustion and emission characteristics of various biofuels, Energy Conversion and Management, 156, p. 235-252, 2018. (doi:10.1016/j.enconman.2017.11.017)

4. Mrzljak, V., Žarković, B., Poljak, I.: Fuel mass flow variation in direct injection diesel engine influence on the change of the main engine operating parameters, Scientific Journal of Maritime Research, 31 (2), p. 119-127, 2017. (doi:10.31217/p.31.2.6)

5. Lee, S., Kim, T. Y.: Performance and emission characteristics of a DI diesel engine operated with diesel/DEE blended fuel, Applied Thermal Engineering, 121, p. 454-461, 2017. (doi:10.1016/j. applthermaleng.2017.04.112)

6. Mrzljak, V., Blažević, S., Anđelić, N., Car, Z.: Exhaust gas emissions from turbocharged direct injection diesel engine during the fuel mass flow variation, Proceedings of International Conference on Innovative Technologies, IN-TECH, Zagreb, Croatia, p. 35-38, 2018.

7. Mrzljak, V., Medica, V., Mrakovčić, T.: Simulation of diesel engine cylinder process using quasidimensional numerical model, Scientific Journal of Maritime Research, 29(2), p. 165-169, 2015. (https://hrcak.srce.hr/149672)

8. Senčić, T., Lucchini, T., Mrzljak, V.: Tuning and validation of a diesel spray model, Transactions of Famena, 34(4), p. 47-58, 2010.

9. Mrzljak, V., Medica, V., Bukovac, O.: Quasi-dimensional diesel engine model with direct calculation of cylinder temperature and pressure, Technical Gazette, 24(3), p. 681-686, 2017. (doi:10.17559/TV-20151116115801)

10. Knox-Kelecy, A.L., Farrell, P.V.: Internal Flow in a Scale Model of a Diesel Fuel Injector nozzle, SAE Paper 922308, 1992. (doi:10.4271/922308)

11. Chaves, H., Knapp, M., Kubitzek, A., Obermeier, F., Schneider, T.: Experimental Study of Cavitation in the Nozzle Hole of Diesel Injectors Using Transparent nozzles, SAE Technical paper 950290, 1995. (doi:10.4271/950290)

12. Madero, J. E., Axelbaum, R. L.: Spray breakup and structure of spray flames for low-volatility wet fuels, Combustion and Flame, 180, p. 102-109, 2017. (doi:10.1016/j.combustflame.2017.02.029)

13. Greenberg, J. B.: Droplet size distribution effects in an edge flame with a fuel spray, Combustion and Flame, 179, p. 228-237, 2017. (doi:10.1016/j.combustflame.2017.02.002)

14. Wu, S., Xu, M., Hung, D. L. S., Pan, H.: Effects of nozzle configuration on internal flow and primary jet breakup of flash boiling fuel sprays, International Journal of Heat and Mass Transfer, 110, p. 730-738, 2017. (doi:10.1016/j.ijheatmasstransfer.2017.03.073)

15. Abianeh, O. S., Chen, C. P., Mahalingam, S.: Numerical modeling of multi-component fuel spray evaporation process, International Journal of Heat and Mass Transfer, 69, p. 44-53, 2014. (doi:10.1016/j.ijheatmasstransfer.2013.10.007)

16. Mrzljak, V., Zarković, B.: Numerical Analysis of the Fuel Spray Packages Penetration and Gas Inflow from Quasi-Dimensional DI Diesel Engine Numerical Model, Journal of the Polytechnic of Rijeka, 7(1), p. 335-357, 2019. (doi:10.31784/zvr.7.1.11) 
17. Guo, M., Nishida, K., Ogata, Y., Wu, C., Fan, Q.: Experimental study on fuel spray characteristics under atmospheric and pressurized cross-flow conditions, second report: Spray distortion, spray area, and spray volume, Fuel, 206, p. 401-408, 2017. (doi:10.1016/j.fuel.2017.05.088)

18. Mrzljak, V., Medica, V., Bukovac, O.: Volume agglomeration process in quasi-dimensional direct injection diesel engine numerical model, Energy, 115, p. 658-667, 2016. (doi:10.1016/j. energy.2016.09.055)

19. Raptotasios, S. I., Sakellaridis, N. F., Papagiannakis, R. G., Hountalas, D. T.: Application of a multi-zone combustion model to investigate the NOx reduction potential of two-stroke marine diesel engines using EGR, Applied Energy, 157, p. 814-823, 2015. (doi:10.1016/j.apenergy.2014.12.041)

20. Mrzljak, V., Medica, V., Bukovac, O.: Simulation of a Two-Stroke Slow Speed Diesel Engine Using a Quasi-Dimensional Model, Transactions of Famena, 2, p. 35-44, 2016. (doi:10.21278/ TOF.40203)

21. Othman, M.F., Adam, A., Najafi, G., Mamat, R.: Green fuel as alternative fuel for diesel engine: A review, Renewable and Sustainable Energy Reviews, 80, p. 694-709, 2017. (doi:10.1016/j. rser.2017.05.140)

22. Jamrozik, A.: The effect of the alcohol content in the fuel mixture on the performance and emissions of a direct injection diesel engine fueled with diesel-methanol and diesel-ethanol blends, Energy Conversion and Management, 148, p. 461-476, 2017. (doi:10.1016/j.enconman.2017.06.030)

23. Moon, S: Novel insights into the dynamic structure of biodiesel and conventional fuel sprays from high-pressure diesel injectors, Energy, 115, p. 615-625, 2016. (doi:10.1016/j.energy.2016.09.062)

24. Azami, M. H., Savill, M.: Modelling of spray evaporation and penetration for alternative fuels, Fuel, 180, p. 514-520, 2016. (doi:10.1016/j.fuel.2016.04.050)

25. Menon, J., Mudgal, B. V.: Experimental determination of contraction coefficient and velocity coefficient for radial gates with elliptical lips, Sådhanå, 43, 61, 2018. (doi:10.1007/s12046-0180818-x)

26. Munson, B., Young, D., Okiishi, T.: Fundamentals of Fluid Mechanics, $5^{\text {th }}$ edition, John Wiley \& Sons, Inc., 2005.

27. Škifić, N.: Influence analysis of engine equipment parameters on diesel engine characteristics, Doctoral Thesis, Rijeka, University of Rijeka, 2003.

28. Cvetić, M.: Combustion modeling in direct injection diesel engine based on fuel injection rate, Doctoral thesis, University of Belgrade, Belgrade, 2000.

29. Von Kuensberg Sarre, C., Song-Charng, K., D. Reitz, R.: Modeling the effects of injector nozzle geometry on diesel sprays, SAE paper 1999-01-0912, 1999. (doi:10.4271/1999-01-0912) 
